\title{
Expression of the brain-type glucose transporter is restricted to brain and neuronal cells in mice
}

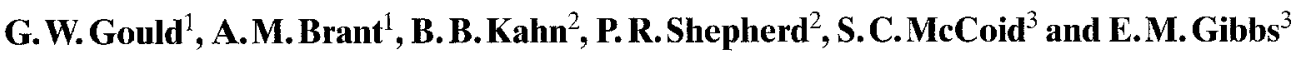 \\ ${ }^{1}$ Department of Biochemistry, University of Glasgow, Glasgow, Scotland, United Kingdom; \\ ${ }^{2}$ Diabetes Unit, Department of Medicine, Beth Israel Hospital and Harvard Medical School, Boston, Massachusetts, and \\ ${ }^{3}$ Pfizer Central Research, Groton, Connecticut, USA
}

\begin{abstract}
Summary. Northern blot analysis of human tissues has demonstrated the expression of the brain-type glucose transporter isoform (GLUT 3 ) in liver, muscle and fat, raising the possibility that this transporter isoform may play a role in the regulation of glucose disposal in these tissues in response to insulin. We have raised an anti-peptide antibody against the C-terminal 13 amino acids of the murine homologue of this transporter isoform, and determined its tissue distribution in mouse tissues and murine-derived cell lines. The antibodies recognise a glycoprotein of about 50 kilodaltons, expressed at high levels in murine brain. In contrast to human tissues, the expression of GLUT 3 in mice is restricted to the brain, and no immunoreactivity was observed in either liver, fat or
\end{abstract}

muscle membranes, or in murine 3T3-L1 fibroblasts or adipocytes. In contrast, high levels of expression of this isoform were observed in the NG 108 neuroblastoma $\mathrm{x}$ glioma cell line, a hybrid cell derived from rat glioma and mouse neuroblastoma cells. Taken together, these data suggest that the expression of GLUT 3 in rodents is restricted to non-insulin responsive neuronal cells and hence it is likely that the factors regulating the expression of this transporter in rodents differ to those in humans.

Key words: Glucose transport, brain-type transporter, diabetes mellitus.
Glucose is a major source of energy for mammalian cells, and a facilitative-diffusion type transport system for glucose is present in the plasma membrane of virtually all animal cells. Recent studies have shown that there is a family of glucose transport proteins, which exhibit considerable homology in their primary sequence, but which are expressed in a distinct, tissue-specific manner [1-3]. This tissue-specific pattern of expression can be rationalised by the specific roles of the particular tissue in the regulation of whole body glucose homeostasis. For example, tissues which exhibit acute insulin-stimulated glucose transport (muscle, fat and heart) express an isoform termed GLUT 4, (or the insulin-responsive transporter), and numerous studies have indicated that it is predominantly this isoform which accounts for the observed increased glucose transport rate in response to insulin [4-10]. Liver, the other major target tissue for insulin expresses a distinct transporter isoform, GLUT 2. This isoform has a high $\mathrm{K}_{\mathrm{m}}$ for glucose, which allows the rate of glucose release from the liver to be increased as the intracellular concentration of glucose is raised [11-13].

To date, studies of the brain-type isoform, GLUT 3, have been restricted to Northern blot analysis in human tissues [14]. In humans, GLUT 3 is expressed at highest levels in the brain. However, its mRNA has also been observed in adipose tissue, liver and muscle, raising the possibility that this isoform may also be important in regulating glucose disposal by these tissues in response to insulin. Recent isolation of the murine cDNA encoding GLUT 3 homologue [15] represents an important advance, since many studies of peripheral insulin resistance utilise rodent models of diabetes and/or obesity, such as the $\mathrm{db} / \mathrm{db}$ mouse or BB rat $[16,17]$. Therefore, in an attempt to evaluate the role of GLUT 3 in glucose homeostasis, we have generated an antibody against the murine homologue of GLUT 3, and used this antibody to determine the sites of expression of GLUT 3 protein in mice, with particular emphasis on liver, muscle and adipose tissue.

\section{Materials and methods}

\section{Materials}

Peptides were synthesised by BioMac Ltd., Department of Biochemistry, University of Glasgow. Sulpho-MBS and ImmunoPure Columns and reagents were from Pierce (Chester, UK). Adjuvant 


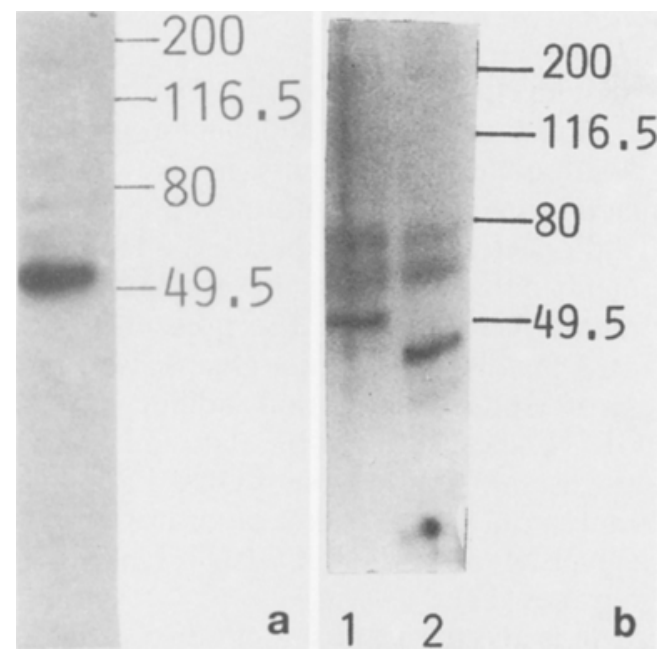

Fig. 1. Immunological identification of GLUT 3 in mouse brain. Panel a: Immunoblot of mouse brain membranes. $12 \mu \mathrm{g}$ of mouse brain membranes were immunoblotted as described, and the blot probed with $10 \mu \mathrm{g} / \mathrm{ml}$ affinity purified anti-GLUT 3 antibodies. The relative position of molecular weight markers is shown to the right of the gel, the entire running gel is shown. Panel b: Effect of glycosidase treatment on GLUT $3.115 \mu \mathrm{g}$ of mouse brain membranes were incubated in the presence (lane 2) or absence (lane 1) of neuraminidase and endoglycosidase $\mathrm{F}$ as described in the materials and methods. Samples containing equal amounts $(10 \mu \mathrm{g})$ of membrane protein were then electrophoresed and immunoblotted as described

was purchased from Difco laboratories (Detroit, Mich., USA). $\left[{ }^{125} \mathrm{I}\right]$ goat anti-rabbit $\mathrm{IgG}$ and $\left[{ }^{3} \mathrm{H}\right]$ cytochalasin $\mathrm{B}$ were from DuPont (Stevenage, UK). Cytochalasin B and E, and Protein A agarose were from Sigma (Poole, UK). Endoglycosidase F and neuraminidase were from Boehringer Mannheim GmbH (Lewes, UK). All other reagents were as described $[13,18,19]$.

\section{Antisera production}

A peptide corresponding to the C-terminal 13 amino acids of the murine homologue of GLUT3 [15], sequence NH2NSMQPVKETPGNA-COOH was coupled to keyhole limpet haemocyanin via sulpho-MBS, utilising an $\mathrm{N}$-terminal cysteine residue incorporated into the peptide [20]. Rabbits were immunised with $250 \mu \mathrm{g}$ of conjugated peptide in $1 \mathrm{ml}$ of a $40 / 60$ mixture of phosphate buffered saline (PBS: $150 \mathrm{mmol} / \mathrm{l} \mathrm{NaCl}, 10 \mathrm{mmol} / \mathrm{l}$ sodium phosphate, $\mathrm{pH}$ 7.4)/Freunds complete adjuvant at multiple intradermal sites. One month later, animals were boosted with the same, but using incomplete Freunds adjuvant. Two weeks later, blood was collected. Antibodies were affinity purified over a column of immobilised peptide using the Pierce ImmunoPure system. Affinity purified antibodies were dialysed overnight against PBS and stored at $-80^{\circ} \mathrm{C}$ prior to use. All experiments reported herein were performed using affinity purified antibodies. The affinity purified GLUT 1 antibodies were the gift of Dr. S. A. Baldwin, Royal Free Hospital, London UK. All antigen injections and sera production was performed by East Acre's Biologicals (Southbridge, Mass. USA).

\section{Immunoblotting}

Proteins were separated on sodium dodecyl sulphate-polyacrylamide gels (SDS-PAGE) as described previously [17]. Following electrophoresis, proteins were transferred to nitrocellulose at $250 \mathrm{mAmps}$ for 2 to $3 \mathrm{~h}$ in $25 \mathrm{mmol} / \mathrm{l}$ sodium phosphate, $\mathrm{pH} 6.5$. Non-specific binding sites on the nitrocellulose were blocked by shaking in $5 \%$ (weight/volume) non-fat milk in wash buffer (PBS containing $1 \mathrm{mmol} / \mathrm{l}$ EDTA and $0.1 \%$ volume/volume Triton X-100) for $30 \mathrm{~min}$. The nitrocellulose was then transferred to $1 \%$ (weight/volume) non-fat milk in wash buffer containing antibody at $10 \mu \mathrm{g} / \mathrm{ml}$ and incubated overnight with shaking. Blots were then developed as described [18].

\section{Preparation of membranes}

Mouse brain membranes. Intact mouse brain tissue was dissected from two mice, homogenised by 20 strokes of a dounce homogeniser in $10 \mathrm{ml}$ of Tris-EDTA buffer $(10 \mathrm{mmol} / \mathrm{l}$ Tris- $\mathrm{HCl} \mathrm{pH} \mathrm{7.5,}$ $1 \mathrm{mmol} / \mathrm{l}$ EDTA). The homogenate was centrifuged at $2,500 \times g_{\max }$ for $10 \mathrm{~min}$ at $4^{\circ} \mathrm{C}$, and the supernatant collected. This supernatant was further centrifuged at $25,000 \times g_{\max }$ for $10 \mathrm{~min}$ at $4^{\circ} \mathrm{C}$ to pellet total membranes. The resulting pellet was washed in Tris-EDTA buffer, centrifuged at $25,000 \times \mathrm{g}_{\max }$ for $10 \mathrm{~min}$ at $4^{\circ} \mathrm{C}$ and the pellet resuspended in $5 \mathrm{ml}$ of Tris-EDTA buffer, and frozen at $-80^{\circ} \mathrm{C}$ prior to use.

Mouse liver membranes. Purified plasma membranes were prepared from total mouse liver homogenates exactly as previously described $[21,22]$.

3T3-L1 adipocyte membranes. 3T3-L1 fibroblasts were grown in culture, and differentiated into adipocytes as previously described [23]. Membrane fractions corresponding to a crude plasma membrane fraction, a high density microsomal and low density microsomal fraction were prepared exactly as previously described [24].

Neuroblastomax glioma NG 108 membranes. Neuroblastoma $\mathrm{x}$ glioma cells were grown in culture and membranes prepared exactly as described [25].

Glycosidase digestion. $115 \mu \mathrm{g}$ of mouse brain membranes were resuspended in $50 \mathrm{mmol} / \mathrm{l}$ potassium phosphate, pH $5.0,20 \mathrm{mmol} / 1$ EDTA, 2\% Triton X-100, 0.2\% SDS, $1 \%$ 2-mercaptoethanol, and incubated for $48 \mathrm{~h}$ with $0.35 \mathrm{U} \mathrm{N}$-glycosidase $\mathrm{F}$ and $5 \mu \mathrm{g}$ neuraminidase at $37^{\circ} \mathrm{C}$. Samples were briefly vortexed throughout the incubation. Following incubation, the proteins were precipitated using trichloroacetic acid, resuspended in SDS-PAGE buffer (see above), and electrophoresed and immunoblotted as described.

\section{Results}

Characterisation of $m G L U T 3$ antibody. Immunoblotting of membranes from mouse brain with affinity-purified anti-GLUT 3 antibodies identified a major band of $M_{r}$ 50 kilodaltons (Fig. 1, panel a). Prolonged exposure of the autoradiogram showed that fainter bands were identified at 55,66 and 76 kilodaltons. The ability of these antibodies to recognise GLUT 3 is also indicated by the fact that cytochalasin B binding was observed in immunoprecipitated GLUT 3 from mouse brain membranes, and that this binding was blocked by $250 \mathrm{mmol} / \mathrm{lD}$-glucose, but not by $250 \mathrm{mmol} / \mathrm{l} \mathrm{L-glucose} \mathrm{(data} \mathrm{not} \mathrm{shown).} \mathrm{These} \mathrm{results}$ are similar to data observed with GLUT 1 and GLUT 4, and indicate that this antibody recognises a glucose transporter of the facilitative diffusion type. Moreover, immunoblotting of the immunoprecipitated protein revealed that only the protein of $\mathrm{M}_{\mathrm{r}} 50$ kilodaltons was immunoprecipitated, suggesting that the fainter bands seen upon prolonged exposure of the immunoblot do not represent modified forms of the mGLUT 3 protein. In a series of 


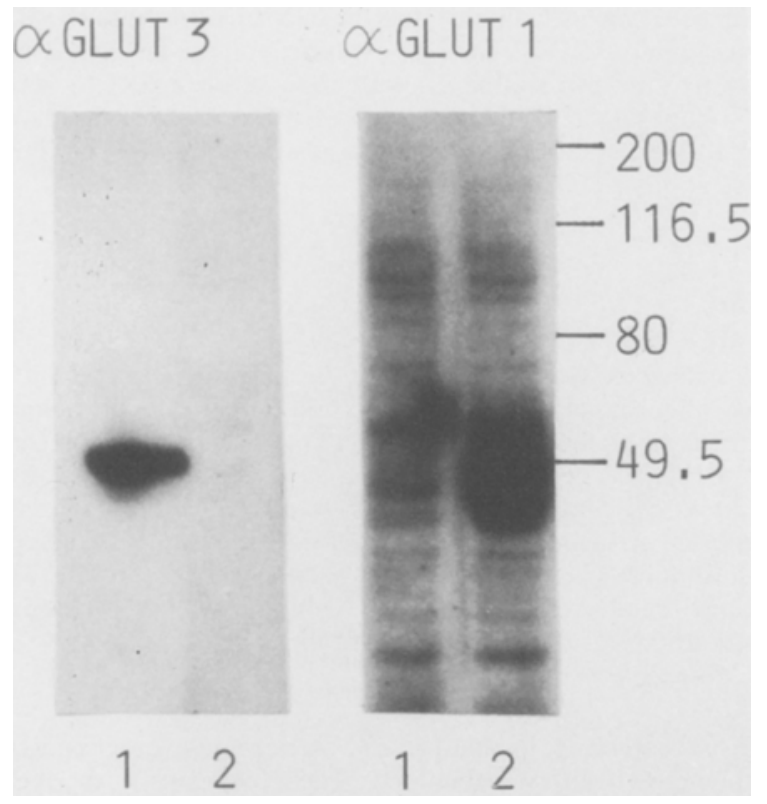

Fig. 2. Peptide competition analysis of mGLUT 3 antibody. $10 \mu \mathrm{g}$ of mouse brain membranes were transferred to nitrocellulose as described, and the immunoblots incubated with either anti-mGLUT 3 or anti-GLUT 1, as indicated. Included in the incubation buffer containing the antibody was $5 \mu \mathrm{g} / \mathrm{ml}$ of the mGLUT 3 peptide (lane 2 in each case) or the GLUT 1 peptide (lane 1). The entire running gel is shown

peptide competition experiments, we have shown that the major immunoreactive band in mouse brain at 50 kilodaltons was effectively competed by $10 \mu \mathrm{g} / \mathrm{ml}$ of the GLUT 3 peptide, but not by a similar concentration of a peptide corresponding to the C-terminal 14 amino acids of GLUT 1 (Fig.2). In addition, the anti-GLUT 1 antibodies recognise a protein of higher molecular weight (about 55 kilodaltons), and the anti-GLUT 1 signal was not affected by the inclusion of $5 \mu \mathrm{g} / \mathrm{ml}$ GLUT 3 peptide, but was effectively blocked by this concentration of GLUT 1 peptide (Fig.2). In experiments not shown here, we have demonstrated that the antibodies raised against the murine GLUT 3 isoform do not immunoblot GLUT 1 or the human isoform of GLUT 3 when expressed in Xenopus oocytes (G.W. Gould, unpublished observations). Taken together, these results indicate that the major immunoreactive protein at 50 kilodaltons recognised by the anti-mGLUT 3 antibodies is indeed mGLUT 3.

The predicted amino acid sequence of the mGLUT 3 contains a potential site for $\mathrm{N}$-linked glycosylation in the extracellular loop located between potential transmembrane helices 1 and 2. Accordingly, we have examined the effect of glycosidases on the electrophoretic mobility of mGLUT 3. Digestion of solubilised mouse brain membranes with the combination of $\mathrm{N}$-glycosidase $\mathrm{F}$ and neuraminidase as described in the Materials and methods caused a decrease in the apparent molecular weight of GLUT 3 to 43 kilodaltons (Fig. 1 panel b), which is consistent with the removal of carbohydrate from the core polypeptide.

\section{Tissue distribution of $m$ GLUT 3}

The distribution of mGLUT 3 was examined by immunoblotting various mouse tissues. No evidence of immunoreactivity at 50 kilodaltons was found in liver (Fig.3, panel b) or in membranes from the murine adipocyte cell line, 3T3-L1 adipocytes (Fig.3, panel a). However, GLUT 1 was readily detected in the same amount of 3T3L1 adipocyte membranes, and was also present in liver membranes (Fig. 3, panel d). The major glucose transporter isoforms expressed in liver and adipocytes are GLUT 2 and GLUT 4 respectively; the data in Figure 3, panel D demonstrates the expression of GLUT 2 in liver plasma membranes, and we and other laboratories have identified high levels of expression of GLUT 4 in 3T3-L1 adipocyte membranes (17).

Skeletal muscle is an important site of peripheral glucose disposal. Consequently we have examined membranes from mouse soleus muscle to characterise transporter expression. The results (Fig. 4) show the expected high levels of GLUT 4 expression, with little or no detectable GLUT 1, and no detectable GLUT 3 expression in samples of 50 and $100 \mu \mathrm{g}$ of membrane protein.

The proposal that the expression of GLUT 3 may be restricted to neuronal tissue prompted an examination of the neuroblastoma $x$ glioma cell line, NG 108 , a mouse $\mathrm{x}$ rat hybrid cell. Immunoblot analysis of this cell line, and also of the rat glioma parental cell is shown in Figure 5, panel A; the mGLUT 3 band of 50 kilodaltons was observed in the hybrid cell line, but not in the glioma. The expression of GLUT 1 was readily detectable in identical amounts of membrane protein (Fig. 5, panel b).

\section{Discussion}

The identification of a family of facilitative glucose transporters has led to a significant advance in the understanding of glucose homeostasis. Of the five glucose transporters cloned to date, all have been functionally expressed in a heterologous system $[4,11,13,19,27,28]$, and their substrate selectivities and kinetics investigated [13]. To further elucidate the contribution of each transporter isoform in the regulation of glucose utilisation by any given tissue, we have raised a panel of anti-peptide antibodies against these different isoforms. The results reported herein concern the GLUT 3, or brain-type isoform. In humans, Northern blot analysis demonstrated the expression of this isoform in many tissues, with highest levels in the brain, but significant levels were also observed in liver, adipose tissue and muscle [14]. The recent isolation of the murine homologue of this isoform [15] prompted us to produce a specific antibody against the murine homologue of this isoform, and to examine the distribution of GLUT 3 in mouse tissues which play important roles in the regulation of blood homeostasis, liver, muscle and fat.

As shown, the antibody recognised a protein of molecular weight of about 50 kilodaltons in mouse brain membranes, which was subsequently shown to be a glucose transporter by the specific immunoprecipitation of D-glu- 


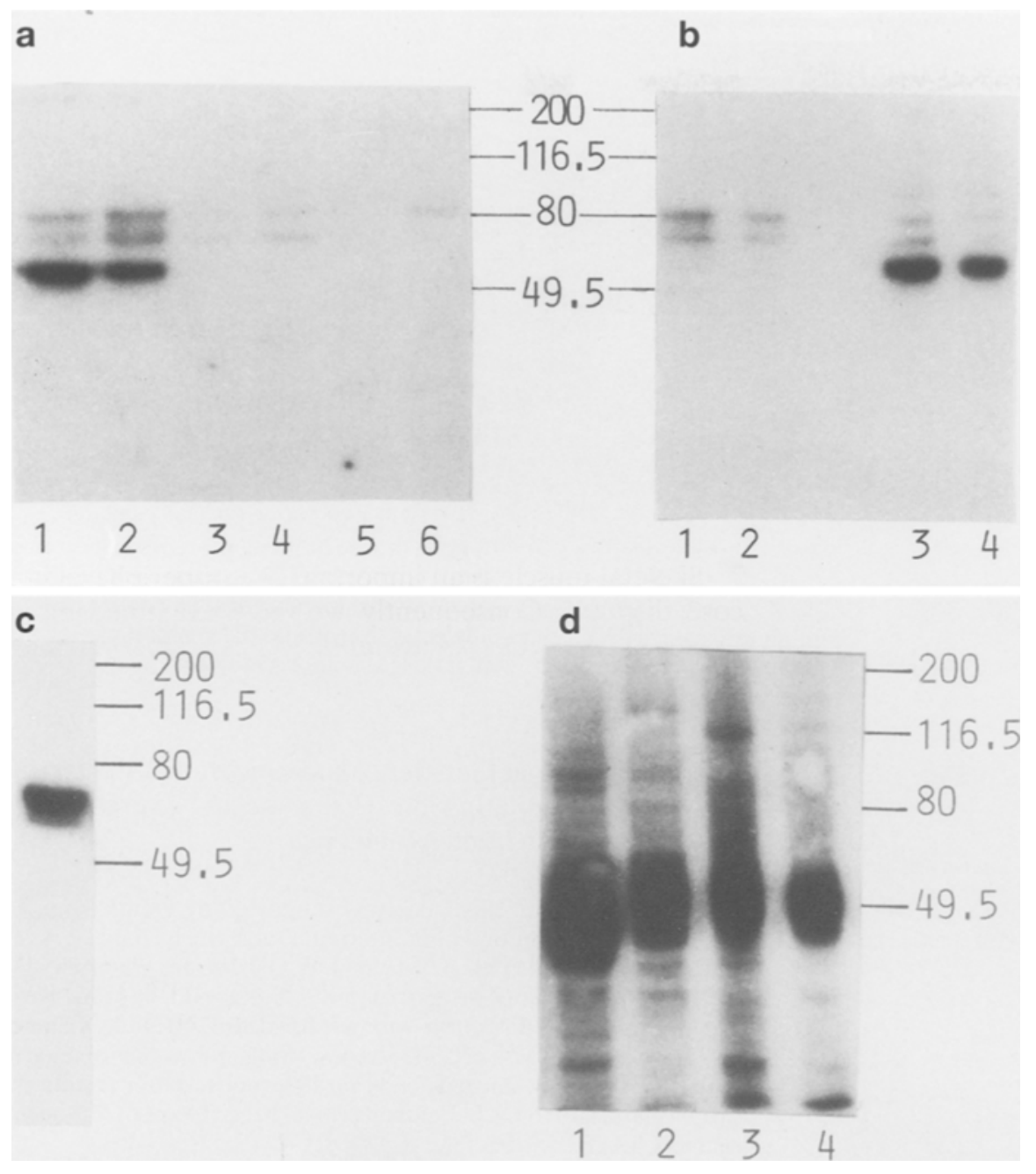

Fig. 3. Tissue distribution of mGLUT 3 - liver and adipocytes. Panel a: 3T3-L1 adipocyte membrane fractions. Samples corresponding to a crude plasma membrane (lanes 3 and 4 ) and the low density microsomal fraction (lanes 5 and 6) from basal (lanes 3 and 5) and insulin-stimulated (lanes 4 and 6) adipocytes were prepared as described. These fractions were immunoblotted $(25 \mu \mathrm{g}$ each lane $)$ with anti-mGLUT 3 antibodies, and the signals compared to that obtained from mouse brain (lanes 1 and 2; 30 and $20 \mu \mathrm{g}$ respectively).

Panel b: Immunoblot analysis of mouse liver plasma membranes. Samples corresponding to 15 and $30 \mu \mathrm{g}$ of mouse liver plasma membranes were immunoblotted as described and the signal compared to mouse brain membranes ( $30 \mu \mathrm{g}$ and $10 \mu \mathrm{g}$, lanes 3 and 4 respectively). In both the above immunoblots, the relative positions of molecular weight markers (in kilodaltons) is shown, and the entire running gel is presented. Panel c: Immunoblot analysis of mouse liver plasma membranes with anti-GLUT 2. Shown is an immunoblot of $5 \mu \mathrm{g}$ of rat liver plasma membranes probed with an antibody raised against the $\mathrm{C}$-terminal 14 amino acids of GLUT 2 . Note the lower protein load used in this immunoblot compared to panels B and D. Panel d: Immunoblot analysis of liver, brain and 3T3-L1 adipocyte membranes with anti-GLUT 1. Samples contain: $25 \mu \mathrm{g}$ of plasma membrane (lane 1) or low density microsomes (lane 2) of 3T3-L1 adipocytes, $30 \mathrm{ug}$ of liver plasma membranes (lane 3) or $10 \mu \mathrm{g}$ of brain membranes

cose inhibitable cytochalasin B binding sites. The antibody also cross-reacted weakly with proteins of higher molecular weight, but these are unlikely to be glucose transporters, as we were unable to label these proteins with cytochalasin B or the photo-activatable glucose analogue, AMB-ATBA (data not shown). Glycosidase digestion, followed by immunoblotting indicated that mGLUT 3 contains an N-linked oligosaccharide, a characteristic feature of the facilitative glucose transporters.

The results of an immunoblot analysis of different murine tissues or cell lines is shown. We observed no immunoreactivity in purified liver plasma membranes, muscle membranes, or membranes prepared from murine 3T3-L1 adipocytes, a cell line often used in the study of insulin-stimulated glucose transport [23]. These data were surprising since Northern blot analysis of human tissues had shown the presence of the GLUT 3 mRNA in many tissues, with levels being highest in brain, but readily detectable in placenta, liver, fat and also present in muscle. These data suggested that the expression of GLUT 3 in mice may be restricted to a smaller subset of tissues. The possibility that mGLUT 3 expression was confined to neuronally-derived cells was examined. Our results also show that GLUT 3 is expressed in the neuroblastoma $\mathrm{x}$ glioma cell line, a hybrid cell derived from rat glioma and murine neuroblastoma cell lines; no immunoreactivity was observed in the parental rat gliomal cells, but GLUT 1 expression was readily detected in these cell lines. These results indicate that the expression of GLUT 3 in mice is restricted to the brain and neurallyderived tissues. It is conceivable that the apparent expression of GLUT 3 observed in liver, muscle and fat from humans may be due to a relatively richer supply of neuronal elements to these tissues in higher mammals.

It is well-established that the major glucose transporter expressed at the blood-nerve and blood-brain barrier is GLUT 1, the erythrocyte-type transporter [29]. Recent studies from this laboratory have examined the kinetics of the human isoforms of GLUT 1 and GLUT 3, and shown that these isoforms, when expressed in Xenopus oocytes, have $\mathrm{K}_{\mathrm{m}}$ 's for 3-O-methyl-D-glucose of 17 and 10.6 $\mathrm{mmol} / \mathrm{l}$ respectively (measured under conditions of equilibrium exchange) [13]. In brain, under normal conditions the capacity of hexokinase for glucose (the prefered energy source) is considerably greater than the capacity of the glucose transport systems in this tissue [30]. However, it may be speculated that under conditions of high glucose demand or hypoglycaemia, the expression of a facilitative 


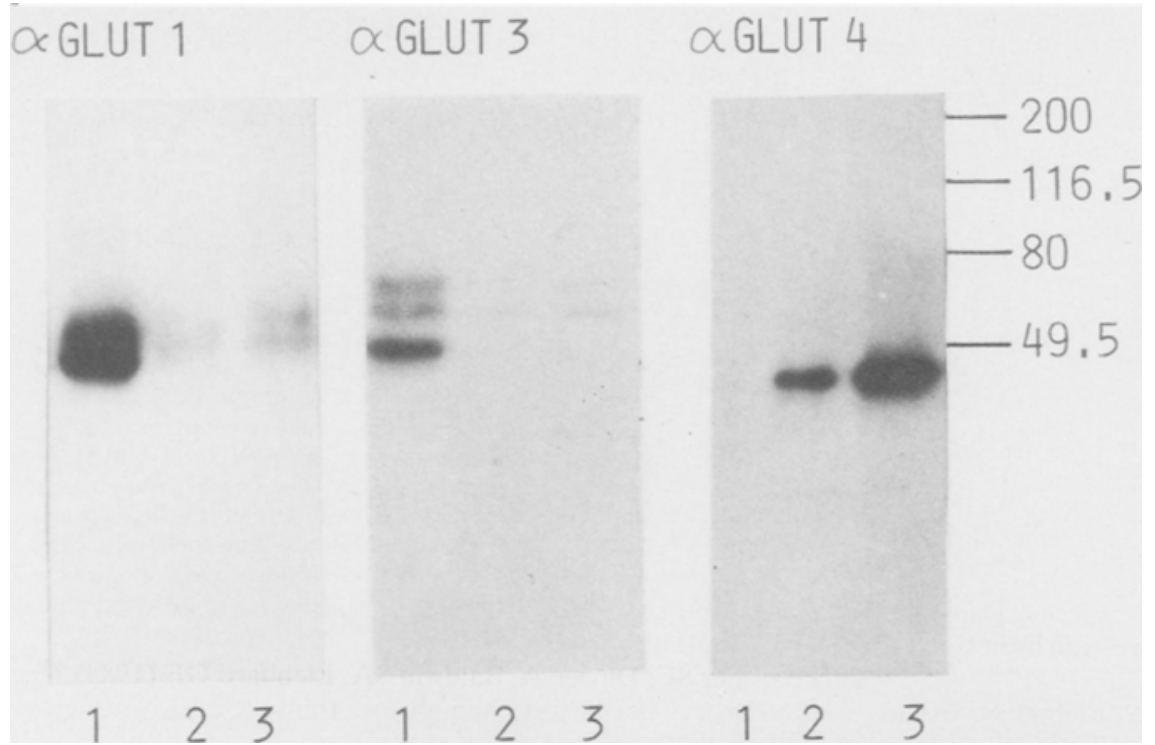

Fig. 4. Tissue distribution of mGLUT 3 muscle membranes. Shown are the results of a series of immunoblots using anti-GLU'T 1 , anti-GLUT 4 or anti-mGLUT 3 against $10 \mu \mathrm{g}$ of mouse brain membranes (lane 1 ), or $50 \mu \mathrm{g}$ (lane 2) and $100 \mu \mathrm{g}$ (lane 3) of mouse soleus muscle membranes. The entire running gel is shown, and the position of molecular weight markers indicated

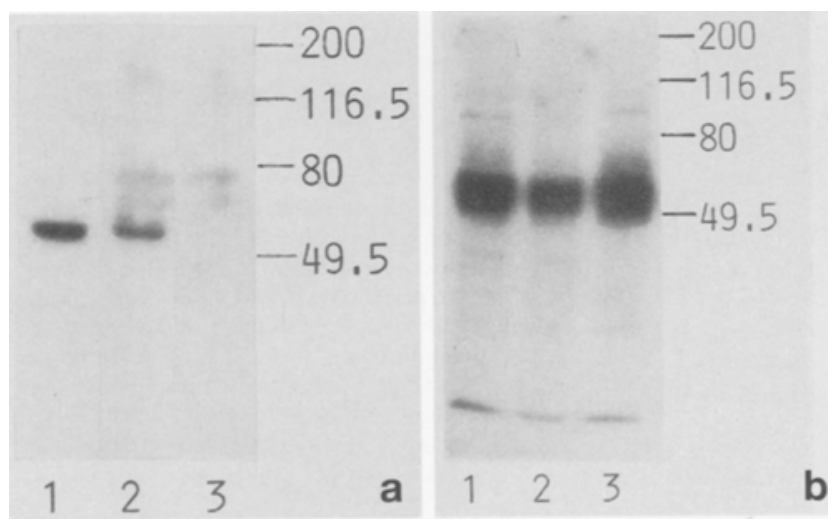

Fig. 5. mGLUT 3 expression in murine neuroblastomas. Panel a: Shown is an immunoblot with anti-mGLUT 3 of mouse brain membranes $(10 \mu \mathrm{g}$, lane 1$)$, neuroblastoma x glioma NG 108 cell membranes ( $25 \mu \mathrm{g}$, lane 2$)$ and rat glioma cell membranes ( $25 \mu \mathrm{g}$, lane 3 ). The entire running gel is shown, and the relative positions of molecular weight markers is indicated to the right of the blot. Panel b: Shown is an identical gel, but probed with anti-GLUT 1 antibodies

glucose transporter in the brain with a low $\mathrm{K}_{\mathrm{m}}$ for hexoses would ensure an efficient uptake of glucose, even when blood glucose is low.

In summary, we have shown that in murine tissues, the expression of the brain-type facilitative glucose transporter, GLUT 3, is restricted to the brain, and probably neurally-derived tissues. No evidence for the expression of this protein in liver, fat or muscle membranes was obtained. These results support the conclusions of Yano et al. [31], who observed no expression of the GLUT 3 isoform in murine tissues other than the brain by Northern blotting using the human GLUT 3 cDNA as a probe. However, unlike GLUTs 1,2 or 4 , the human and murine homologues of GLUT 3 differ, showing only $83 \%$ identity [19], compared to the greater than $95 \%$ identity in the case of GLUT 1 [1-3]. Consequently, the results presented here using a species-specific probe for the expressed protein provide further support for this group's results. Taken together, these data suggest that the factors involved in regulating the tissue-specific expression of GLUT 3 differ in humans and mice.

Acknowledgements. This work was supported by grants from the Juvenile Diabetes Foundation International, British Diabetic Association and the Wellcome Trust (to G. W. G.). We are grateful to Dr. G.Bell (University of Chicago) for providing us with the sequence of the murine GLUT 3 isoform prior to publication, to Dr. I. Mullaney and Mr. C. Carr (University of Glasgow) for generously providing us with NG 108 cells, and advice regarding mouse brain membrane preparation, and to Dr. S. Baldwin (Royal Free Hospital) for the gift of anti-GLUT 1 antibodies.

\section{References}

1. Gould GW, Bell GI (1990) Facilitative glucose transporters: an expanding family. Trends Biochem Sci 15: 18-23

2. Mueckler M (1990) Glucose transporter family: implications for glucose homeostasis and diabetes. Diabetes 39: 6-11

3. Bell GI, Kayano T, Buse JB et al. (1990) Molecular biology of mammalian glucose transporters. Diab Care 13: 198-208

4. Birnbaum MJ (1989) Identification of a novel gene encoding an insulin-regulatable glucose transport protein. Cell 57: 305-315

5. James DE, Strube M, Mueckler M (1989) Molecular cloning and characterisation of an insulin-regulatable glucose transporter. Nature (London) 338: 83-87

6. Zorzano A, Wilkinson W, Kotlair, $\mathrm{N}$ et al. (1989) Insulin-regulated glucose uptake in rat adipocytes is mediated by two transporter isoforms present in at least two vesicle populations. J Biol Chem 264: 12358-12363

7. Calderhead DM, Kitagawa K, Tanner LI, Holman GD, Lienhard GE (1990) Insulin regulation of two glucose transporters in 3T3L1 adipocytes. J Biol Chem 265: 13800-13808

8. Holman GD, Kozka IJ, Clark AE et al. (1990) Cell surface labelling of glucose transporter isoform GLUT 4 by bis-mannose photolabel. J Biol Chem 265: 18172-18279

9. Garvey WT, Heucksteadt TP, Birnbaum MJ (1989) Pretranslational suppression of an insulin-responsive glucose transporter in rats with diabetes mellitus. Science 245: 60-63

10. Sivitz WI, DeSautel SL, Kayano T, Bell GI, Pessin JE (1989) Regulation of glucose transporter messenger RNA in insulin deficient states. Nature (London) 340: 72-74 
11. Thorens B, Sarkar HK, Kaback HR, Lodish HF (1988) Cloning and functional expression in bacteria of a novel glucose transporter present in liver, intestine, kidney and $\beta$-pancreatic islet cells. Cell 55: 281-290

12. Fukumoto H, Seino S, Imura H et al. (1988) Sequence, tissue-distribution and chromosomal localisation of mRNA encoding a human glucose transporter-like protein. Proc Natl Acad Sci USA 85: $5434-5438$

13. Gould GW, Thomas HM, Jess TJ, Bell GI (1991) Expression of human glucose transporters in Xenopus oocytes: kinetic characterisation and substrate specificites of the erythrocyte, liver and brain isoforms. Biochemistry 30: 5139-5145

14. Kayano T, Fukumoto H, Eddy RL et al. (1988) Evidence for a family of human glucose transporter-like proteins: sequence and gene localisation of a protein expressed in fetal skeletal muscle and other tissues. J Biol Chem 263: 15245-15248

15. Nagamatsu S, Kornhauser JM, Burant CF, Seino S, Mayo KE, Bell GI (1992) Glucose transporter expression in brain: cDNA sequence of mouse GLUT 3, the brain facilitative glucose transporter isoform, and identification of sites of expression by in situ hybridisation. J Biol Chem 267: 467-472

16. Coleman DL (1978) Obesity and diabetes: two mutant genes causing diabetes-obesity syndromes in mice. Diabetologia 14: 141-148

17. Tominaga M, Komiya I, Johnson JH et al. (1986) Loss of insulin response to glucose but not arginine during the development of autoimmune diabetes in $\mathrm{BB} / \mathrm{W}$ rats: relationships to islet volume and glucose transport rate. Proc Natl Acad Sci USA 83: 97499753

18. Gibbs EM, Calderhead DM, Holman GD, Gould GW (1991) Phorbol ester on partially mimics the effects of insulin on glucose transport and glucose transporter translocation in 3T3-L1 adipocytes. Biochem J 275: 145-150

19. Gould GW, Lienhard GE (1989) Expression of a functional glucose transporter in Xenopus oocytes. Biochemistry 28: 94479452

20. Lerner RA (1981) Chemically synthesised peptides predicted from the nucleotide sequence of the hepatitis B virus genome elicit antibodies reactive with the native envelope protein of Dane particles. Proc Natl Acad Sci USA 78: 3403-3407

21. Pilkis SJ, Exton JH, Johnson RA, Park CR (1974) Effects of glucagon on cyclic AMP and carbohydrate metabolism in livers from diabetic rats. Biochim Biophys Acta 343: 250-267

22. Marchmont RJ, Ayad SR, Houslay MD (1981) Purification and properties of the insulin-stimulated cyclic AMP phosphodiesterase from rat liver plasma membranes. Biochem J 195: 645-652
23. Frost SC, Lane MD (1985) Evidence for the involvement of vicinal sulphydryl groups in insulin-activated hexose transport in 3T3-L1 adipocytes. J Biol Chem 260: 2646-2652

24. Gould GW, Lienhard GE, Tanner LI, Gibbs EM (1989) Phenylarsine oxide stimulates hexose transport in 3T3-L1 adipocytes by a mechanism other than an increase in surface transporters. Arch Biochem Biophys 268: 264-275

25. Hamprecht B, Glasser T, Reiser G, Bayer E, Propst F (1985) Culture and characteristics of hormone-responsive neuroblastoma $\mathrm{x}$ glioma hybrid cells. Meth Enzymol 109: 316-341

26. Clark AE, Holman GD (1990) Exofacial labelling of the human erythrocyte glucose transporter with an azitrifluoroethyl benzoyl-substituted bis -mannose. Biochem J 269: 615-622

27. Vera JC, Rosen OR (1989) Functional expression of mammalian glucose transporters in Xenopus oocytes: evidence for cell dependent insulin-sensitivity. Mol Cell Biol 9: 4187-4195

28. Gould GW, Derechin V, James DE et al. (1989) Insulin-stimulated translocation of the HepG2/erythrocyte-type glucose transporter expressed in 3T3-L1 adipocytes. J Biol Chem 264: 2180-2184

29. Froehner SC, Davies A, Baldwin SA, Lienhard GE (1988) The blood-nerve barrier is rich in glucose transporter. J Neurocytol 17: $173-178$

30. Clarke DD, Lajitha AL, Maker HS (1981) Intermediary metabolism. In: Siegel G, Agranoff B, Albers RW, Molinoff P(eds) Basic Neurochemistry, 4th Edition. Raven Press, New York, pp 541564

31. Yano H, Seino Y, Inagaki N et al. (1991) Tissue distribution and species difference in the expression of the brain-type glucose transporter, GLUT 3. Biochem Biophys Res Comm 174: 470477

Received: 30 August 1991

and in revised form: 7 November 1991

Dr. G. W. Gould

Department of Biochemistry

University of Glasgow

Glasgow G12 8QQ

Scotland

UK 